\title{
Highly diverse population of Picornaviridae and other members of the Picornavirales, in Cameroonian fruit bats
}

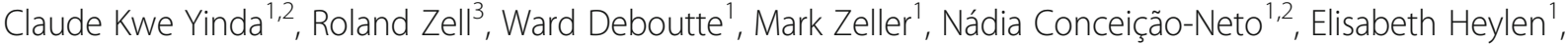 \\ Piet Maes ${ }^{2}$, Nick J. Knowles ${ }^{4}$, Stephen Mbigha Ghogomu ${ }^{5}$, Marc Van Ranst ${ }^{2}$ and Jelle Matthijnssens ${ }^{1 *}$
}

\begin{abstract}
Background: The order Picornavirales represents a diverse group of positive-stranded RNA viruses with small nonenveloped icosahedral virions. Recently, bats have been identified as an important reservoir of several highly pathogenic human viruses. Since many members of the Picornaviridae family cause a wide range of diseases in humans and animals, this study aimed to characterize members of the order Picornavirales in fruit bat populations located in the Southwest region of Cameroon. These bat populations are frequently in close contact with humans due to hunting, selling and eating practices, which provides ample opportunity for interspecies transmissions.

Results: Fecal samples from 87 fruit bats (Eidolon helvum and Epomophorus gambianus), were combined into 25 pools and analyzed using viral metagenomics. In total, Picornavirales reads were found in 19 pools, and (near) complete genomes of 11 picorna-like viruses were obtained from 7 of these pools. The picorna-like viruses possessed varied genomic organizations (monocistronic or dicistronic), and arrangements of gene cassettes. Some of the viruses belonged to established families, including the Picornaviridae, whereas others clustered distantly from known viruses and most likely represent novel genera and families. Phylogenetic and nucleotide composition analyses suggested that mammals were the likely host species of bat sapelovirus, bat kunsagivirus and bat crohivirus, whereas the remaining viruses (named bat iflavirus, bat posalivirus, bat fisalivirus, bat cripavirus, bat felisavirus, bat dicibavirus and bat badiciviruses 1 and 2) were most likely diet-derived.
\end{abstract}

Conclusion: The existence of a vast genetic variability of picorna-like viruses in fruit bats may increase the probability of spillover infections to humans especially when humans and bats have direct contact as the case in this study site. However, further screening for these viruses in humans will fully indicate their zoonotic potential.

Keywords: Bat, Picornavirales, Picornaviruses, Virome, Unbiased sequencing

\section{Background}

The order Picornavirales consists of viruses with a monopartite or bipartite positive strand RNA genome of the families Dicistroviridae, Iflaviridae, Marnaviridae, Secoviridae, Picornaviridae, the genera Bacillarnavirus and Labyrnavirus as well as many other proposed unassigned species, all of which possess small nonenveloped icosahedral virions of approximately $30 \mathrm{~nm}$ in diameter with a pseudo $\mathrm{T}=3$ symmetry $[1,2]$. A major

\footnotetext{
* Correspondence: jelle.matthijnssens@kuleuven.be

${ }^{1}$ Department of Microbiology and Immunology, Rega Institute for Medical Research, Laboratory of Viral Metagenomics, KU Leuven - University of Leuven, Leuven, Belgium

Full list of author information is available at the end of the article
}

characteristic of this order includes the presence of a three-domain replication block (Hel-Pro-Pol domains including a superfamily III helicase, a chymotrypsin-like proteinase and an RNA-dependent RNA polymerase, respectively). The genomic organization of members of this order is variable. In the families Picornaviridae and Iflaviridae, the replication block is found in the Cterminal region of the polyprotein, while the structural proteins are in the $\mathrm{N}$-terminal region, all encoded within a monocistronic genome (except for members of the dicistronic Dicipivirus genus of the family Picornaviridae). In others, such as the Marnaviridae and Dicistroviridae, the reverse order is true and can either be on a 
single (monocistronic) open reading frame (Marnaviridae) or on two separate (dicistronic) open reading frames (ORFs) (Dicistroviridae, Bacillarnavirus, Labyrnavirus) [3]. The family Secoviridae contains viruses with either monopartite genomes with the replication block at the $\mathrm{N}$-terminus or bipartite genomes [4]. Of all, only viruses of the family Picornaviridae have been implicated in human and other vertebrate diseases such as gastroenteritis, meningitis, encephalitis, paralysis (nonpolio and polio-type), myocarditis, hepatitis, upper respiratory tract infections and diabetes $[5,6]$.

Recently, members of the order Picornavirales have been discovered in stools of different animals: feline stool-associated RNA virus (fesavirus) from cats in an animal shelter [7]; fish stool-associated RNA virus (fisavirus) in the intestinal content of a carp [8]; porcine stool-associated RNA viruses (posaviruses) in the feces of healthy pigs $[9,10]$ and human stool-associated RNA viruses (husavirus) in stools of HIV positive and negative patients [11]. Moreover, the RdRP of most of these novel viruses clustered with a cDNA sequence found in Ascaris suum [12], suggesting that this cDNA would have come from a virus infecting the parasite [9]. Viruses of this order are known to infect vertebrates, arthropods, higher plants, fungi and algae. Here we report the identification and genomic characterization of 11 highly diverse near/complete picorna-like genomes from Eidolon helvum fruit bat.

\section{Methods}

\section{Sample collection and preparation}

Fecal samples were collected from fruit bats between December 2013 and May 2014 as previously described in $[13,14]$. Briefly, bats were captured in three different regions (Lysoka, Muyuka and Limbe) of the South West Region of Cameroon using mist nets around fruit trees. Each bat was held in paper sack for 5 to 20 minutes allowing enough time for fresh feces to be produced after which the bats were released. Then, 25 pools were made from 87 collected samples (85 from Eidolon helvum and 2 from Epomophorus gambianus) and the pools were treated to enrich for viral particles using the NetoVIR protocol [15]. Sequencing of the samples was performed on a HiSeq 2500 platform (Illumina) for 300 cycles (2x150 bp paired ends). Additional PCRs (list of primers can be found in Additional file 1: Table S1) and Sanger sequencing (Applied Biosystems) was performed to: 1) complete gaps in the obtained genomes, or 2) to verify genomic regions covered by less than 5 sequence reads.

\section{Genomic and phylogenetic analysis}

NGS reads were analyzed as described in Yinda et al. $[13,14]$. Briefly, after raw reads were trimmed, de novo assembled and contigs annotated, open reading frames (ORF) were identified and further analyzed for conserved motifs identification in the amino acid sequences using NCBI's conserved domain database (CDD) [16], Pfam [17] and Phyre2 [18]. Nucleotide alignments of the viral sequences were done with Muscle implemented in MEGA5 and adjusted manually [19]. For phylogenetic tree inference, four Bayesian Metropolis-coupled Markov chains were calculated with MrBayes version 3.1.2 [20, 21] using an optimal substitution model. Sequences used in the phylogenetic analysis were representatives of the different families or unassigned members of the order Picornavirales. All sequences were deposited in GenBank under the accession numbers KX644936-KX644946. Raw reads were submitted to the NCBI's Short Read Archive (SRA) under the project ID PRJNA344863 (https://www.ncbi.nlm.nih.gov/bioproject/ PRJNA344863/).

\section{Nucleotide composition analysis (NCA)}

To infer the host of the viruses we identified, we used NCA as described in [22]. Briefly, all complete picornalike genomes (segmented and non-segmented) whose host information is known were retrieved from VirusHost DB [23] on the 1st of October 2016. Segmented genomes were concatenated together and treated as a single genome. Subsequently, all viruses that infect multiple hosts were removed, and only those infecting mammals, plants or insects were retained, resulting in a list of 351 genomes. A list of accession numbers for genomes used in NCA analysis is provided in Additional file 1: Table S2. Mononucleotide and dinucleotide frequencies for each genome were determined using an inhouse developed python script. From these frequencies, the dinucleotide bias was calculated as described in [24]. Discriminant analysis was performed and the figure was created in R [25] using the MASS [26] and ggplot2 [27] packages, respectively. Briefly, the mononucleotide frequencies and dinucleotide bias for all possible dinucleotide combinations were used as discriminators. Furthermore, we used the predict function from the stats package [25]. The classification and posterior probabilities were calculated using the predicted linear discriminant analysis (LDA) model.

\section{Results}

Illumina sequencing of 25 bat pools generated approximately 696 thousand non-phage viral reads of which $10 \%$ were assigned to the order Picornavirales (other viruses include those of the order/family Astroviridae, Caliciviridae, Circoviridae, Coronaviridae, Papillomaviridae, Partitiviridae, Picobirnaviridae, Parvoviridae, Reoviridae, Tymovirales, Table 1). Six of the pools (P6, P7, P12, P13, P19 and P20) had no reads for viruses of 
Table 1 Number of reads belonging to members of the order Picornavirales and percentages to total number of non-phage viral reads

\begin{tabular}{|c|c|c|c|c|c|c|}
\hline Pool & $\begin{array}{l}\text { Total non-phage } \\
\text { viral reads }\end{array}$ & Picorna-like reads & $\%$ Picorna-like reads & Virus described & $\begin{array}{l}\text { Viral reads percentage } \\
\text { of picorna-like reads }\end{array}$ & $\begin{array}{l}\text { Other viruses found in the } \\
\text { pool (see figure legend) }\end{array}$ \\
\hline P1 & 7068 & 178 & 2.5 & - & - & 2,9 and 12 \\
\hline \multirow[t]{3}{*}{$P 2^{\mathrm{a}}$} & \multirow[t]{3}{*}{71955} & \multirow[t]{3}{*}{2964} & \multirow[t]{3}{*}{4.1} & bat kunsagivirus & 30.1 & \multirow[t]{3}{*}{1,9 and 11} \\
\hline & & & & bat posalivirus & 44.4 & \\
\hline & & & & bat dicibavirus & 25.5 & \\
\hline P3 & 82029 & 936 & 1.1 & - & - & 9 and 14 \\
\hline$P 4^{\mathrm{a}}$ & 72953 & 8951 & 12.3 & bat felisavirus & 95.7 & $4,6,7,9,12$ and 15 \\
\hline P5 & 1206 & 7 & 0.6 & - & - & 8,9 , and 16 \\
\hline P6 & 450 & 0 & 0 & - & - & 9 \\
\hline P7 & 7156 & 0 & 0 & - & - & $4,9,11,14$ and 15 \\
\hline P8 & 53007 & 613 & 1.2 & - & - & 11, 14and 15 \\
\hline P9 & 20866 & 70 & 0.3 & - & - & 2 and 4 \\
\hline P10 & 46295 & 35 & 0.1 & - & - & $2,4,6,11$ and 15 \\
\hline $\mathrm{P} 11^{\mathrm{a}}$ & 60856 & 52661 & 86.5 & bat badicivirus 1 & 98.2 & 4,6 and 15 \\
\hline P12 & 787 & 0 & 0 & - & - & $2,4,6,11$ and 15 \\
\hline P13 & 2016 & 0 & 0 & - & - & 4,6 and 15 \\
\hline P14 & 50567 & 1032 & 2 & - & - & $2,3,12$ and 17 \\
\hline P15 & 108737 & 747 & 0.7 & - & - & $3,12,15$ and 17 \\
\hline $\mathrm{P} 16^{\mathrm{b}}$ & 110542 & 586 & 0.5 & - & - & 3 and 9 \\
\hline \multirow[t]{2}{*}{$\mathrm{P} 17^{\mathrm{a}}$} & \multirow[t]{2}{*}{227525} & \multirow[t]{2}{*}{90976} & \multirow[t]{2}{*}{40} & bat iflavirus & 94.4 & \multirow[t]{2}{*}{9,11 and 14} \\
\hline & & & & bat cripavirus & 3.7 & \\
\hline P18 & 1372 & 18 & 1.3 & - & - & $9,11,14,16$ and 17 \\
\hline P19 & 4334 & 0 & 0 & - & - & $9,11,12,14$ and 17 \\
\hline P20 & 626 & 0 & 0 & - & - & $4,6,11,14,15$, and 17 \\
\hline P21 & 19222 & 1331 & 6.9 & - & - & $4,6,11,14,15$ and 17 \\
\hline \multirow[t]{2}{*}{$\mathrm{P} 22^{\mathrm{a}}$} & \multirow[t]{2}{*}{569516} & \multirow[t]{2}{*}{6705} & \multirow[t]{2}{*}{1.2} & bat badicivirus 2 & 35.6 & \multirow[t]{2}{*}{2 and 17} \\
\hline & & & & bat fisalivirus & 41.9 & \\
\hline P23 & 620965 & 1351 & 0.2 & - & - & 4 \\
\hline $\mathrm{P} 24^{\mathrm{a}}$ & 3107 & 1214 & 39.1 & bat sapelovirus & 83.7 & $1,2,3,5,11,14,15$ and 17 \\
\hline$P 25^{\mathrm{a}}$ & 15355 & 1319 & 8.6 & bat crohivirus & 100 & $3,4,8,11,14,15$ and 17 \\
\hline
\end{tabular}

${ }^{a}$ Indicate pool from which (near) complete picorna-like virus genomes are described; - indicate cells corresponding to pools without picorna-like sequences or picorna-like viruses described. ${ }^{b}$ only pool with Epomophorus gambianus samples. Other viruses present are numbered as follows: $1=$ Astroviridae, $2=$ Caliciviridae, $3=$ Circoviridae, $4=$ Coronaviridae, $5=$ Hepeviridae, $6=$ Herpesviridae, $7=$ Nodaviridae, $8=$ Papillomaviridae, $9=$ Partitiviridae, $10=$ Paramyxoviridae, $11=$ Parvoviridae, $12=$ Picobirnaviridae, $14=$ Reoviridae, $15=$ Retroviridae, $16=$ Totiviridae, $17=$ Tymovirales

the Picornavirales order while pool 11 (P11) had the highest number of reads (52 thousand reads, $86.5 \%$ of the non-phage viral reads) (Table 1 ). We were able to obtain 11 (near) complete genomes of these viruses, which we named: bat kunsagivirus, bat crohivirus, bat sapelovirus, bat iflavirus (slow bee paralysis virus-like), bat posalivirus (posavirus-like), bat fisalivirus (fisaviruslike), bat cripavirus (Himetobi $\mathrm{P}$ virus-like), bat felisavirus (fesavirus-like), bat dicibavirus (JP-A-like), bat badiciviruses 1 and 2 (Aphis glycine virus-like) (explanation of the novel names is found in Table 2). Additionally, reads specific to kobuvirus (aichivirus A, mouse and Eidolon helvum
Table 2 Explanation of novel proposed names

\begin{tabular}{ll}
\hline Name of virus & Explanation \\
\hline Posalivirus & Posa-like virus \\
Fisalivirus & Fisa-like virus \\
Felisa-virus & $\begin{array}{l}\text { from fesa-like virus (Fesalivirus) to avoid confusion } \\
\text { with fisalivirus }\end{array}$ \\
Badicivirus & $\begin{array}{l}\text { bat dicistrovirus } \\
\text { Dicibavirus }\end{array}$ \\
& $\begin{array}{l}\text { anagram from bat dicistrovirus because this virus } \\
\text { has exchanged CP and Hel-Prot-Pol domains }\end{array}$ \\
\hline
\end{tabular}


kobuvirus), teschovirus, boone cardiovirus, torradovirus, sequivirus, waikavirus, and cripavirus/aphid lethal paralysis virus were detected. The number of reads of the (near) completely sequenced viral genomes ranged from 893 to 85,849 . The number of reads for each of these viral genomes and the percentage of picorna-like reads from the total non-phage viral reads present in each pool can be found in column 3 and 4 of Table 1 . All these sequences were substantially divergent from their closest known relatives and in the cases were closely related reference genomes were lacking, we are not certain of the completeness of the 5'-ends.

The organization of these viral genomes varied greatly. Bat kunsagivirus, bat crohivirus, bat sapelovirus, bat iflavirus, bat posalivirus and fisalivirus possess monocistronic genomes, whereas bat cripavirus, bat felisavirus, bat dicibavirus and bat badiciviruses 1 and 2 all possess dicistronic genomes (Fig. 1).

The bat kunsagivirus genome exhibits a genome organization typical for members of the family Picornaviridae and it is at least 7092-nt long with a single ORF (7050 nt) flanked by at least a 393-nt long 5' UTR and a 41-nt long 3' UTR (Table 3 and Fig. 1a). Although it is likely that approximately 100 nucleotides at the 5 '-end of the bat kunsagivirus genome are still missing, the similarity of the type IV IRES structures of roller kunsagivirus proposed in [21] and the bat kunsagivirus (Fig. 2a) is evident. The ORF displays the typical picornaviral genome layout with the Hel-Pro-Pol domains located downstream from the picornaviral structural protein domains (Fig. 1a). The proposed proteolytic cleavage sites of bat kunsagivirus were mapped based on the alignment with the monocistronic European roller kunsagivirus (roller/SZAL6-KuV/2011/HUN) sequence (KC935379) and they are shown in Fig. 1a (with arrows). The deduced polyprotein precursor has three capsid proteins (1AB, 1C, 1D ranging from aa 1 to 299,300 to 527 and 528 to 765 , respectively) each with a conserved picornavirus-like capsid protein (rhv) domain. The polyprotein lacks both an obvious leader polypeptide and a myristoylation signal found in many picornaviruses. Similar to the arrangement found in the genome of roller kunsagivirus (KC935379), two gene regions encoding 2A proteins were predicted: $2 \mathrm{~A} 1$ is a 23 aa long aphthovirus-like protein whereas $2 \mathrm{~A} 2$ is 175 aa long without similarity to known proteins. The bat kunsagivirus $2 \mathrm{~A} 2$ was 10 amino acids longer than the roller kunsagivirus 2A2 (175 vs. 165 aa) and did not exhibit the conserved amino acids of the protein kinase $\mathrm{C}$ superfamily as suggested previously [28]. Likewise, no similarity of the $3 \mathrm{C}$-terminal sequence and $3 \mathrm{~B}$ sequence was observed in the bat kunsagivirus questioning the significance of the previous findings which suggested existence of a conserved motif in this region
[28]. The genome contained all of the conserved amino acid motifs of picornaviral $2 \mathrm{C}$ helicase, $3 \mathrm{C}$ proteinase and 3D RNA polymerase and showed the highest sequence identity (57\% aa identity) to roller kunsagivirus in the $3 \mathrm{D}$ region (Table 4). However, the predicted bat kunsagivirus $3 \mathrm{C}$ is 19 aa shorter and $3 \mathrm{D}$ is 33 aa longer than the respective proteins of roller kunsagivirus. These combined findings suggest that the kunsagiviruses of bat and roller belong to different species.

Bat crohivirus (BtCroV) is the second monocistronic picornavirus identified and its genome showed the same organization as the yet unclassified shrew crohivirus and the genus Pasivirus (Fig. 1b) in the family Picornaviridae. We obtained a near complete genome of $7081 \mathrm{nt}$ (Table 3), although it seems that a few nucleotides at the 5 ' and 3' ends are missing. The genome contains a predicted single large ORF encoding a putative polyprotein of 2173 aa, although the initiation codon (AUG) was not located in the Kozak consensus sequence (AAGAUGG) like in the CroV-1 genome [29]. The ORF is bordered by a 508 nt long 5' UTR and 54 nt long 3' UTR and the potential polyprotein cleavage sites are as shown in Fig. 1b. The BtCroV genome contained motifs of an aphthovirus-like $2 \mathrm{~A} 1$ and a second $2 \mathrm{~A}$ protein with unknown function. All of the conserved amino acid motifs of the picornaviral $2 \mathrm{C}$ helicase, $3 \mathrm{C}$ proteinase and $3 \mathrm{D}$ RNA polymerase were present (Table 4 ). The 3D polymerase showed $50 \%$ sequence identity to the shrew crohivirus (AB937989).

The third picorna-like sequence identified was a sapelovirus, exhibiting a genome length of at least 7572 nt with a single ORF of 2173 aa between at least a 20 nt 5'-UTR and 111 nt 3'-UTR ends (Table 3 and Fig. 1c). Based on prediction tools, the genome organization of bat sapelovirus showed similar features to sapelovirus A1 (former porcine sapelovirus 1) [30]. The predicted polyprotein is preceded by a leader protein of 185 aa, and has a long 2A protein of about 246 aa (20 aa longer than of sapelovirus A1). Most of the replication protein motifs are conserved (GxxGxGKS motif for nucleoside triphosphate binding sites of $2 \mathrm{C}$; $\mathrm{GxCGx}_{10} \mathrm{GxHxxG}$ motif of $3 \mathrm{C}$ proteinase and the KDE, PSG, YGDD and FLKR motifs of RNA-dependent RNA polymerase) except DYSNWD of the RdRP that differs from sapelovirus A1 RdRp at position 3 (DYTNWD) (Table 4). Proposed proteolytic cleavage sites of bat sapelovirus were mapped based on the alignment with sapelovirus A1 (AF406813) and are shown in Fig. 1c with arrows.

We also identified sequences related to the slow bee paralysis virus of the family Iflaviridae tentatively named bat iflavirus. The genome is at least $10520 \mathrm{nt}$ long and contains a 3179 aa ORF flanked by at least $28 \mathrm{nt}$ and 
A Bat kunsagivirus: Family Picornaviridae

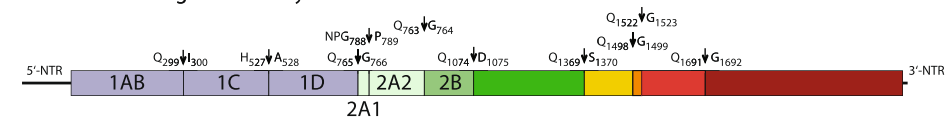

B Bat crohivirus: Family Picornaviridae
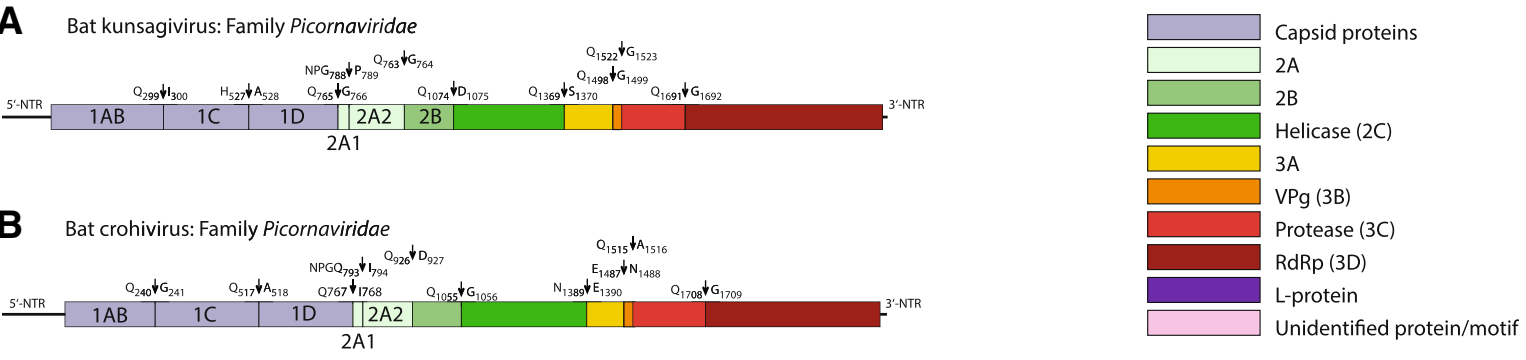

C Bat sapelovirus: Family Picornaviridae

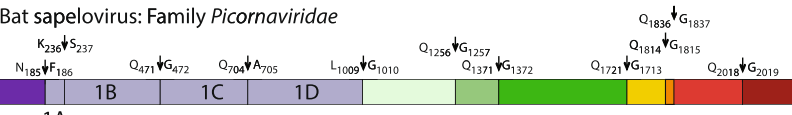

$1 \mathrm{~A}$

D Bat iflavirus: Family Iflaviridae

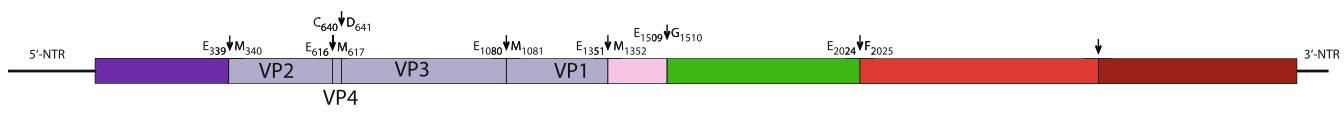

E Bat posalivirus: Family unassigned

* Motifs identified with Phyre2

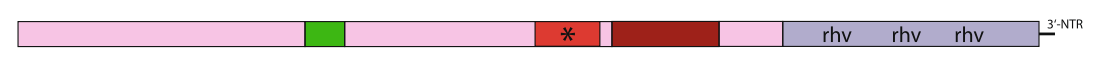

F Bat fisalivirus: Family unassigned

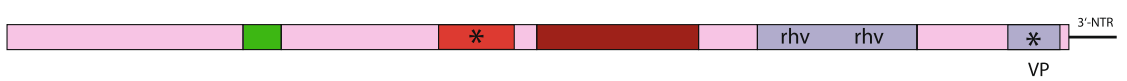

G Bat cripavirus: Family Dicistroviridae

$E_{177} s_{178}$

$E_{164} 4 A_{165}$

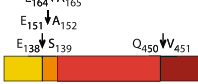

$3 \times \mathrm{VPg}$

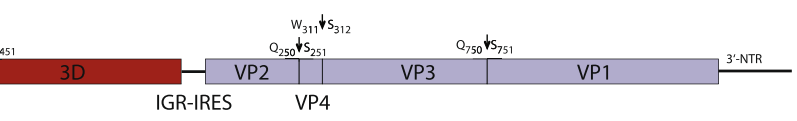

H Bat felisavirus: Family unassigned

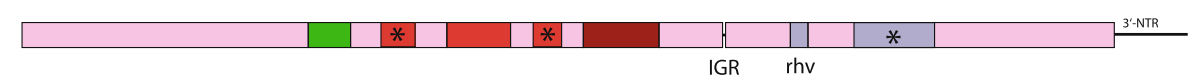

I Bat dicibavirus: Family unassigned

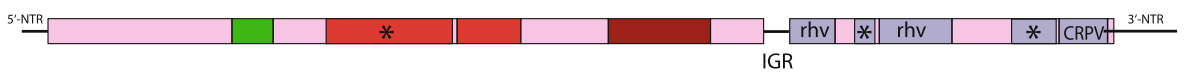

J Bat badicivirus 1: Family unassigned

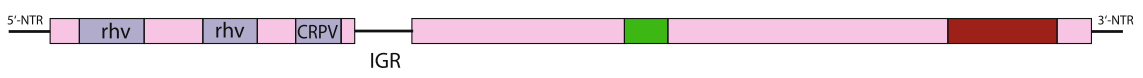

$\mathbf{K} \quad$ Bat badicivirus 2: Family unassigned

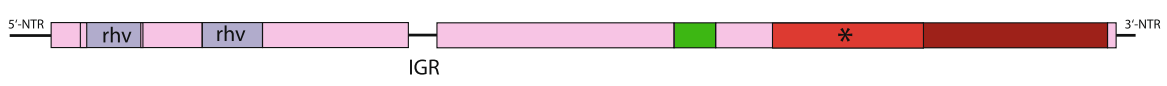

Scale bar

$\stackrel{\text { Scale bar }}{\longleftarrow}=1000 \mathrm{nt}$

Fig. 1 (See legend on next page.) 
(See figure on previous page.)

Fig. 1 The genome organization and conserved picornaviral motifs of (a) bat kunsagivirus; (b) bat crohivirus; (c) bat sapelovirus; (d) bat iflavirus; (e) bat posalivirus; (f) bat fisalivirus 2; (g) bat cripavirus; (h) bat felisavirus; (i) bat dicibavirus; (j) bat badicivirus 1 and (k) bat badicivirus 2 . The proposed cleavage sites of bat kunsagivirus, crohivirus, sapelovirus and iflavirus are indicated with arrows. Conserved motifs were identified with CDD [16], Pfam [17], and Phyre2 [18]. Proposed cleavage sites of the polyprotein of kunsagivirus, crohivirus, sapelovirus and iflavirus are indicated with arrows and amino acid position

$273 \mathrm{nt}$ at the 5'-UTR and 3'-UTR, respectively (Table 3). Like other iflaviruses, genes coding for structural proteins are located in the N-terminus of the ORF whereas those encoding the replication proteins are located at the Cterminal part (Fig. 1d). This genome organization is typical of members of the insect-specific virus family Iflaviridae, and more in particular for slow bee paralysis virus (SBPV, EU035616). Arrows in Fig. 1d indicate where the predicted polyprotein of bat iflavirus is processed into functional units based on an alignment with SBPV. The polyprotein is preceded by a leader protein of 176 aa at the $\mathrm{N}$-terminus, followed by four capsid proteins. An unidentified protein of 148 aa (aa position 11551303) bridges the structural proteins and the replication block made up of Hel-Prot-Pol with the conserved motifs GxxGxGKS, GxCGx ${ }_{16}$ GxHxxG, KDY, DYSNFG, ASG, YGDD and FLKR, respectively (Table 4).
Bat posalivirus and fisalivirus possess a single large ORF with the replication proteins at the $\mathrm{N}$-terminus and capsid proteins at $\mathrm{C}$-terminus (Fig. $1 \mathrm{e}$ and $\mathrm{f}$ ). The 5'-ends of both viral sequences (5'-UTR and the Nterminal part of the polyprotein) are lacking. Posalivirus exhibits a genome length of at least $8341 \mathrm{nt}$ with a long ORF of at least 8213 nucleotide (nt); the 3'-UTR is $127 \mathrm{nt}$ long (Table 3). The genome layout corresponds to that of posaviruses 1 and 2 (JF713720, JF713721), fisavirus 1 (KM434233) and husavirus (KT215901, KT215902, KT215903). The posalivirus genome showed conserved domains of the RNA helicase (aa 766-870) and the RdRP (aa 1583-1867) (Fig. 1e). The NCBI BLASTP failed to detect conserved sequences that were unequivocally identified as protease domain. However, there is an amino acid stretch with the sequence $\mathrm{GDCGX}_{15} \mathrm{GMY}$ which is thought to extend

Table 3 Genome characteristics of novel viruses and the corresponding representative species

\begin{tabular}{|c|c|c|c|c|c|c|}
\hline Strain & Genome type & Genome size (\#nt) & 5'-UTR (\#nt) & 3'-UTR (\#nt) & ORF (\#aa) & IGR (\#nt) \\
\hline Bat kunsagivirus & monocistronic & 7092 & 393 & 42 & 2218 & NA \\
\hline Kunsagivirus A1 (KC935379) & monocistronic & 7272 & 500 & 25 & 2248 & NA \\
\hline Bat crohivirus & monocistronic & 7081 & 508 & 54 & 2173 & NA \\
\hline Crohivirus (AB937989) & monocistronic & 7321 & 517 & 293 & 2343 & NA \\
\hline Bat sapelovirus & monocistronic & 7572 & 150 & 152 & 2481 & NA \\
\hline Sapelovirus (AF406813) & monocistronic & 7491 & 443 & 51 & 2321 & NA \\
\hline Bat iflavirus & monocistronic & 10520 & 28 & 273 & 3179 & NA \\
\hline Slow bee paralysis virus (NC_014137) & monocistronic & 9505 & 316 & 293 & 2965 & NA \\
\hline Bat Posalivirus $^{a}$ & monocistronic & 8343 & - & 128 & 2737 & NA \\
\hline Posavirus 1 (JF713720) & monocistronic & 9840 & 829 & 152 & 2952 & NA \\
\hline Bat fisalivirus $^{a}$ & monocistronic & 8862 & - & 382 & 2826 & NA \\
\hline Fisavirus (KM434233) & monocistronic & 8712 & 395 & 57 & 2753 & NA \\
\hline Bat cripavirus $^{a}$ & monocistronic & 6939 & - & 587 & ORF1: >972 ; ORF2: 1233 & 190 \\
\hline Himetobi P virus (AB017037) & dicistronic & 9275 & 963 & 588 & ORF1: 1778 ; ORF2: 874 & 174 \\
\hline Bat felisavirus virus ${ }^{\mathrm{a}}$ & dicistronic & 9299 & - & 588 & ORF1: >1879 ; ORF2: 1006 & 23 \\
\hline Fesavirus 1 (KM017736) & monocistronic & 6218 & - & 829 & 1743 & NA \\
\hline Bat dicibavirus & dicistronic & 8882 & 120 & 249 & ORF1: 1770; ORF2: 860 & 199 \\
\hline Marine JP-A virus (EF198241) & dicistronic & 9236 & 632 & 434 & ORF1: 1689; ORF2: 984 & 146 \\
\hline Bat badicivirus 1 & dicistronic & 8325 & 332 & 230 & ORF1: 806; ORF2: 1623 & 459 \\
\hline Aphis glycines virus 1 (KF360262) & dicistronic & 8305 & - & 113 & ORF1: 776; ORF2: 1794 & 474 \\
\hline Bat badicivirus 2 & dicistronic & 8637 & 352 & 155 & ORF1: 827; ORF2: 1806 & 229 \\
\hline
\end{tabular}

- 5'UTR could not be obtained for this virus; \#nt: number of nucleotides; \#aa: number of amino acid; aincomplete genomes 


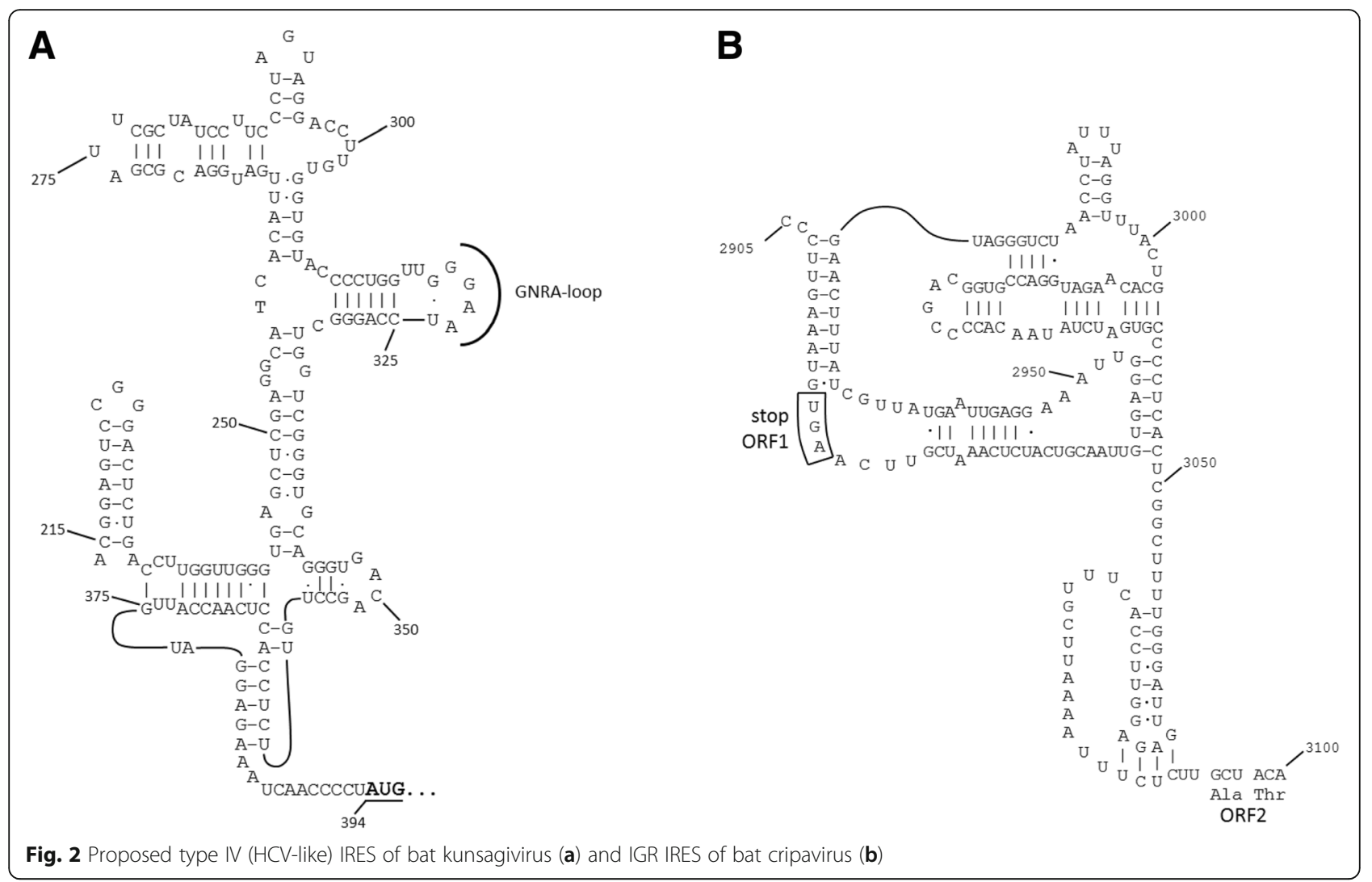

the conserved GXCGX $_{n} \mathrm{GXH}$ sequence motif of the peptidase C3 superfamily. Thus, it is likely that the deduced protein exhibits proteinase activity. There are three rhv-like domains, with domains 1 and 3 lacking conserved amino acids of the so-called "drug-binding pocket". In addition, the genome contained motifs of multidrug and toxic compound extrusion (MATE) domains usually found only in bacteria [31]. The fisalivirus is similar to fisavirus 1 (KM434233) with a genome length of at least $8862 \mathrm{nt}$ and a $382 \mathrm{nt}$ noncoding region at the 3 '-UTR. There is an ORF of at least 2420 aa with a genome organization like that of posalivirus except that it lacked sequences with detectable homology to a third rhv domain.

Apart from the monocistronic picorna-like viruses above, we also identified five Picornavirales genomes with a dicistronic organization.

Firstly, the bat cripavirus genome contained two predicted ORFs of 2919 nts (ORF1) and 3702 nts (ORF2) encoding replication proteins and structural proteins, respectively (Fig. 1g). There seemed to be a portion missing at the 5' end of the ORF1. However, three copies of the genome-linked protein $(\mathrm{VPg})$ at the aa positions 139-151, 152-164 and 165-177 as well as the consensus motifs for an RNA-dependent RNA polymerase (KDE, DFEGFD, PSG, LGDD and YLKR), were found in the deduced amino acid sequence (Table 4). The two ORFs are separated by a short intergenic region (IGR) of $190 \mathrm{nt}$ that is supposed to form an internal ribosome entry site (IRES) (Fig. 2b) typical of the Cripavirus genus [32] and therefore clearly defines this virus as a cripavirus. ORF2 contains four predicted capsid protein motifs (three rhinovirus-like capsid protein domains (rhv) and one cricket paralysis virus (CRPV) capsid proteinlike motif) at aa positions 1-250, 251-311, 312-750 and 751-1233, respectively.

The bat felisavirus is a dicistronic virus with a predicted ORF1 (5638 nt) encoding functional proteins and ORF2 (3020 nt) encoding capsid proteins. Both ORFs are separated by a very short intergenic region (IGR) of $73 \mathrm{nt}$ (Fig. 1h). The 5'-end of the genome (5' UTR and N-terminal sequences of the polyprotein) could not be obtained. The 3' UTR has the remarkable length of $588 \mathrm{nt}$ (Table 3). ORF1 exhibits conserved sequences of a P-loop NTPase (RNA helicase, 764875 aa) with a $\mathrm{G}_{768} \mathrm{XXGXGKT}$ consensus sequence (Walker motif A), a proteinase (1129-1317 aa) with a conserved GXCGX ${ }_{16}$ GXH motif and an RdRP (15101710 aa) with conserved KDE, PSG, YGDD and FLKR motifs (Table 4). ORF2 showed only a short stretch of 45 aa with weak similarity to a rhv domain (137-182 aa) (Fig. 1h). 
Table 4 Genome functional motifs in the 3CD region of novel viral genomes and the corresponding representative species

\begin{tabular}{|c|c|c|c|c|c|c|c|}
\hline Strain & Helicase & Proteinase & & Polyme & ase & & \\
\hline Bat kunsagivirus & 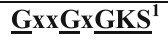 & $\underline{\mathbf{G}} \underline{\mathbf{C G}} x_{14} \underline{G} x \underline{H} x \underline{G}$ & $\underline{\text { KDE }}$ & 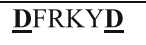 & $\underline{\text { PSG }}$ & $\underline{\text { YGDD }}$ & $\underline{\text { FLKR }}$ \\
\hline Kunsagivirus A1 (KC935379) & $\underline{G} x \underline{\mathbf{G} x \underline{G K S}}$ & $\underline{\mathbf{G}} \underline{\mathbf{C G}} x_{14} \mathbf{A} \times \underline{H} x \underline{G}$ & $\underline{\text { KDE }}$ & $\underline{\mathbf{D F S K F}} \underline{\mathrm{D}}$ & $\underline{\text { PSG }}$ & $\underline{\text { YGDD }}$ & $\underline{\text { FLKR }}$ \\
\hline Bat crohivirus & $\underline{\mathbf{G} x x} \underline{\mathbf{G} x \underline{G K S}}$ & 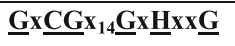 & $\underline{\text { KDE }}$ & $\underline{\mathbf{D Y T G Y}} \underline{\mathbf{D}}$ & $\underline{\text { PSG }}$ & $\underline{\text { YGDD }}$ & $\underline{\text { FLKR }}$ \\
\hline Crohivirus (AB937989) & $\underline{\text { GxxG }} \underline{\mathbf{G}} \underline{\mathbf{G K S}}$ & $\underline{\mathbf{G}} \times \underline{\mathbf{C G}} \mathbf{x}_{14} \underline{\mathbf{G}} \times \underline{H} \times x \underline{G}$ & $\underline{\text { KDE }}$ & $\underline{\mathbf{D} Y T G Y \underline{\mathbf{D}}}$ & $\underline{\text { PSG }}$ & $\underline{\text { YGDD }}$ & FLKR \\
\hline Bat sapelovirus & $\underline{\text { GxxG }} \underline{\text { GKKS }}$ & $\underline{\mathbf{G}} \underline{\mathbf{C G}} x_{10} \underline{\mathbf{G}} \underline{\mathrm{H}} \times x \underline{G}$ & $\underline{\text { KDE }}$ & DYSNW $\underline{\mathbf{D}}$ & $\underline{\text { PSG }}$ & YGDD & FLKR \\
\hline Sapelovirus (AF406813) & $\underline{\text { GxxGxGKS }}$ & $\underline{\mathbf{G}} \underline{\mathbf{C G}} \mathbf{x}_{10} \underline{\mathbf{G}} \underline{\mathbf{H}} \times \underline{x} \underline{\mathbf{G}}$ & $\underline{\text { KDE }}$ & DYTNWD & $\underline{\text { PSG }}$ & $\underline{\text { YGDD }}$ & $\underline{\text { FLKR }}$ \\
\hline Bat iflavirus & $\underline{\mathbf{G} x x} \underline{\mathbf{G}} \underline{\underline{G K S}}$ & $\underline{\mathbf{G}} \underline{\mathbf{C G}} x_{16} \underline{\mathbf{G}} \underline{\mathbf{H}} \times x \underline{G}$ & $\underline{\text { KDY }}$ & DYSNFG & $\mathrm{A} \underline{\mathbf{S G}}$ & $\underline{\text { YGDD }}$ & $\underline{\text { FLKR }}$ \\
\hline Slow bee paralysis virus (NC_014137) & 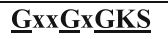 & $\underline{G x} \underline{C G x} x_{16} \underline{G} \underline{H} x x \underline{G}$ & $\underline{\mathrm{KD}} \mathrm{Y}$ & $\underline{\text { DYANFG }}$ & $\mathrm{A} \underline{\underline{\mathbf{S G}}}$ & $\underline{\text { YGDD }}$ & $\underline{\text { FLKR }}$ \\
\hline Bat Posalivirus & $\underline{G} \times \underline{G} x \underline{G K T}$ & $\underline{\mathbf{G}} \underline{\mathbf{C G} x_{15}} \underline{\mathbf{G}} \times \underline{Y} \times \underline{x} \underline{\mathbf{G}}$ & $\underline{\text { KDE }}$ & 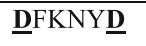 & C]SG & LGDD & $\underline{\text { FLGA }}$ \\
\hline Posavirus 1 (JF713720) & $\underline{\mathbf{G} x} \underline{\mathbf{G}} \underline{\underline{G K T}}$ & $\underline{\mathbf{G}} \underline{\mathbf{C G}} x_{15} \mathbf{A} \times \underline{H} \times \underline{G}$ & $\underline{\text { KDE }}$ & $\underline{\mathbf{D Y S G F}} \underline{\mathbf{D}}$ & $\underline{\text { PSG }}$ & LGDD & FLGS \\
\hline Bat fisalivirus & xxxGxGKS & $\underline{\mathbf{G}} \underline{\mathbf{C G}} x_{15} \underline{\mathbf{G}} \underline{\mathbf{H}} \times \underline{\underline{G}}$ & $\underline{\text { KDE }}$ & 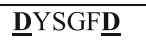 & $\underline{\text { PSG }}$ & LGDD & FLGS \\
\hline Fisavirus (KM434233) & xxx $\underline{\text { GxGKT }}$ & $\underline{G} \underline{\mathbf{C G}} x_{16} \underline{G} \underline{\operatorname{H}} x x \underline{G}$ & $\underline{\text { KDE }}$ & 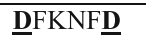 & FSG & LGDD & FLGA \\
\hline Bat cripavirus & --- & $\mathbf{T} \times \underline{C G} x_{16} \underline{G} \underline{\operatorname{H}} \times x \underline{G}$ & $\underline{\text { KDE }}$ & $\underline{\text { DFEGFD }}$ & $\underline{\text { PSG }}$ & LGDD & YLKR \\
\hline Himetobi P virus (AB017037) & $\underline{G} \times \underline{G} x \underline{G K S}$ & $\underline{\mathbf{G}} \underline{\mathbf{C G}} x_{16} \underline{\mathbf{G}} \underline{\mathbf{H}} \times x \underline{G}$ & $\underline{\text { KDE }}$ & $\underline{\mathbf{D} F E G F \underline{\mathbf{D}}}$ & $\underline{\text { PSG }}$ & LGDD & YLKR \\
\hline Bat felisavirus virus & 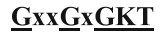 & $\underline{\mathbf{G}} \underline{\mathbf{C G}} \mathbf{x}_{16} \underline{\mathbf{G}} \underline{\mathbf{H}} \times \mathbf{S}$ & $\underline{\text { KDE }}$ & $\underline{\mathbf{D M S G W}} \underline{\mathbf{D}}$ & $\underline{\text { PSG }}$ & $\underline{\text { YGDD }}$ & $\underline{\text { FLKR }}$ \\
\hline Fesavirus 1 (KM017736) & --- & $\underline{\mathbf{G}} \underline{\mathbf{C G}} x_{16} \underline{\mathbf{G}} \underline{\operatorname{H}} x x \underline{G}$ & $\underline{\text { KDE }}$ & $\underline{\mathbf{D} Y G G W \underline{\mathbf{D}}}$ & $\underline{\text { PSG }}$ & $\underline{\text { YGDD }}$ & $\underline{\text { FLKR }}$ \\
\hline Bat dicabavirus & $\underline{\text { Gxxxx } \underline{G K S}}$ & $\underline{\mathbf{G x}} \underline{\mathrm{C}} \mathbf{M} \mathrm{x}_{13} \underline{\mathbf{G}} \underline{\mathrm{H}} \times x_{\underline{G}}$ & $\underline{\text { KDE }}$ & $\underline{\mathbf{D} Y S K Y \underline{\mathbf{D}}}$ & $\underline{\text { PSG }}$ & $\underline{\text { YGDD }}$ & $\underline{\text { FLKR }}$ \\
\hline Marine JP-A virus (EF198241) & 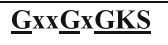 & $\underline{\mathbf{G}} \underline{\mathbf{C G}} \mathbf{x}_{13} \underline{\mathbf{G}} \underline{\mathbf{H}} \times x \underline{\mathbf{G}}$ & $\underline{\text { KDE }}$ & $\underline{\mathbf{D} Y S K Y} \underline{\mathbf{D}}$ & $\underline{\text { PSG }}$ & $\underline{\text { YGDD }}$ & $\underline{\text { FLKR }}$ \\
\hline Bat badicivirus 1 & $\underline{G} \times \underline{G x} \underline{G K S}$ & $\underline{\mathbf{G}} \times \underline{\mathrm{S}} \underline{\mathbf{G}} x_{16} \underline{\mathbf{G}} \times \mathrm{Q} \times x \underline{I}$ & $\underline{\text { KDE }}$ & $\underline{\mathbf{D} Y S D W} \underline{\mathbf{D}}$ & KSG & $\underline{\text { YGDD }}$ & $\underline{\text { FLKR }}$ \\
\hline Aphis glycines virus 1 (KF360262) & $\underline{G x x} \underline{\mathbf{G x}} \mathbb{R} \underline{\mathbf{K S}}$ & $\underline{\mathbf{G}} \mathbf{S} \underline{\mathbf{G}} \mathbf{x}_{15} \underline{\mathbf{G}} \times \mathrm{Q} \times \mathbf{R}$ & $\underline{\text { KDE }}$ & $\underline{\mathbf{D} Y K N W \underline{\mathbf{D}}}$ & C]SG & $\underline{\text { YGDD }}$ & $\underline{\text { FLKR }}$ \\
\hline Bat badicivirus 2 & $\underline{G} x \underline{G x} \underline{G K S}$ & $\underline{\mathbf{G}} \underline{\mathbf{C G}} x_{15} \underline{\mathbf{G}} \times \underline{\mathrm{L}} \times \mathrm{A}$ & $\mathbf{K S} \mathbf{E}$ & $\underline{\mathbf{D} Y S S W \underline{\mathbf{D}}}$ & $\mathrm{N} \underline{\mathrm{SG}}$ & $\underline{\text { YGDD }}$ & $\underline{\text { FLKR }}$ \\
\hline
\end{tabular}

Bat dicibavirus is a dicistronic virus that resembles viruses of the genus Bacillarnavirus which presumably infect diatoms. The ORF1 encodes functional proteins, containing conserved domains of an RNA helicase (aa 432-541) with a $\mathrm{GX}_{4} \mathrm{GKS}$ Walker $\mathrm{A}$ motif and a RsdvnGiyidD Walker B motif of P-loop NTPases, a proteinase (aa 1030-1198) with a GLCMX ${ }_{13}$ GXH motif also found in other bacillarnaviruses and an RdRP (aa 14301701) with KDE, PSG, YGDD and FLKR motifs (Table 4). The ORF2 encodes two domains with homology to rhv (61-232 and 349-542 aa) and one with similarity to the CRPV (cricket paralysis virus) domain (827-955 aa) also found in dicistroviruses of insects. Rhv domain 1 also has some similarity to the calicivirus coat protein superfamily. Both ORFs are separated by a short intergenic region (IGR) of $196 \mathrm{nt}$ (Fig. 1i). There seemed to be no
RNA structures representing an IGR-IRES, however, ORF2 starts with a glycine codon which is typical of IGR-IRES driven translation initiation [33].

Surprisingly, two dicistronic picorna-like viruses with a 5' ORF encoding capsid proteins and a 3' ORF coding for the replication proteins were identified and provisionally named bat badiciviruses 1 and 2 (Fig. 1j, k). The bat badicivirus 1 ORF1 encodes three putative capsid proteins and is flanked by a 5'-UTR of at least $332 \mathrm{nt}$ and an intergenic region of 459 nucleotides (Table 3) and ORF2 is followed to a 3' UTR of 242 nucleotides (Fig. 1j). The capsid proteins exhibit similarity to rhv domains (aa 78-250 and aa 414-552) and the CRPV capsid superfamily (aa 602-687). In ORF2, only an RNA helicase domain (378-493 aa) and an RdRp domain (12411532 ) were predicted. Instead of a GXCGX $_{n} G X H$ motif 
of 3C-like proteinases, we observed the sequence GQSGX $_{16}$ GVAI suggesting an active site serine residue. The genome of bat badicivirus 2 comprises at least 8637 nt. The two ORFs are separated by a 229 nt IGR. ORF1 (333-2753 nt) encodes two conserved motifs of rvh (between 95-250 aa and 396-555 aa, respectively) while ORF2 (3061-8481 nt) was predicted to encode replication proteins: RNA helicase (634-743 aa), peptidase (2012-2290 aa) and an RdRP (1295-1785 aa). The 5'-UTR and 3'-UTR ends contain 352 and 155 nt, respectively.

Phylogenetic analysis was performed using the nucleotide sequences of the proteinase-polymerase domains (3CD) of the eleven novel viruses, and 60 representative members of the order Picornavirales (Fig. 3). The phylogenetic tree confirmed the BLAST results and showed (i) clustering of bat kunsagivirus, bat crohivirus and bat sapelovirus with their cognate picornavirus genera [i.e., Kunsagivirus A1 (roller/SZAL6-KuV/2011/HUN, KC935379) Crohivirus 1 (shrew/ZM54/Zambia/2012, AB937989) and sapelovirus A1 (PEV8-V13, AF406813), respectively]; (ii) close clustering of bat iflavirus with slow bee paralysis virus (EU035616) and other members of the Iflaviridae (deformed wing virus, AJ489744; infectious flacherie virus, AB000906; sacbrood virus, AF092924; ectropis obliqua virus, AY365064); (iii) bat posalivirus and fisalivirus forming a clade of unassigned viruses comprising posaviruses 1 and 2 (JF713720 and JF713721), fisavirus 1 (KM434233), husavirus (KT215901-KT215903) and Pow Burn virus (KU754519); (iv) bat cripavirus, the only virus of the family Dicistroviridae described in this study formed a clade with cripavirus (NB-1/2011/HUN, KJ802403) and Himetobi P virus (AB017037) within the genus Cripavirus, family Dicistroviridae; (v) bat felisavirus, bat dicibavirus and bat badiciviruses 1 and 2 clustered to yet unassigned viruses. Bat felisavirus was closest to fesavirus 1 (KM017736) while bat badiciviruses 1 and 2 formed a cluster with Aphis glycines virus 1 (KF360262) and soybean-associated bicistronic virus (KM015260), with very low sequence identity even in the most conserved parts of the genome; (vi) finally, bat dicibavirus clustered with the diatom-specific Chaetoceros tenuissimus RNA virus type-II SS10-16 V (AB971661), Chaetoceros sp. RNA virus 2 Csp02RNAV01 (AB639040), marine RNA virus JP-A (EF198241), Asterionellopsis glacialis RNA virus (AB973945) and antarctic picorna-like virus 2 (KM259870), though clearly distant from these viruses (34-53\% amino acid identity of $3 \mathrm{D}^{\mathrm{pol}}$ ).

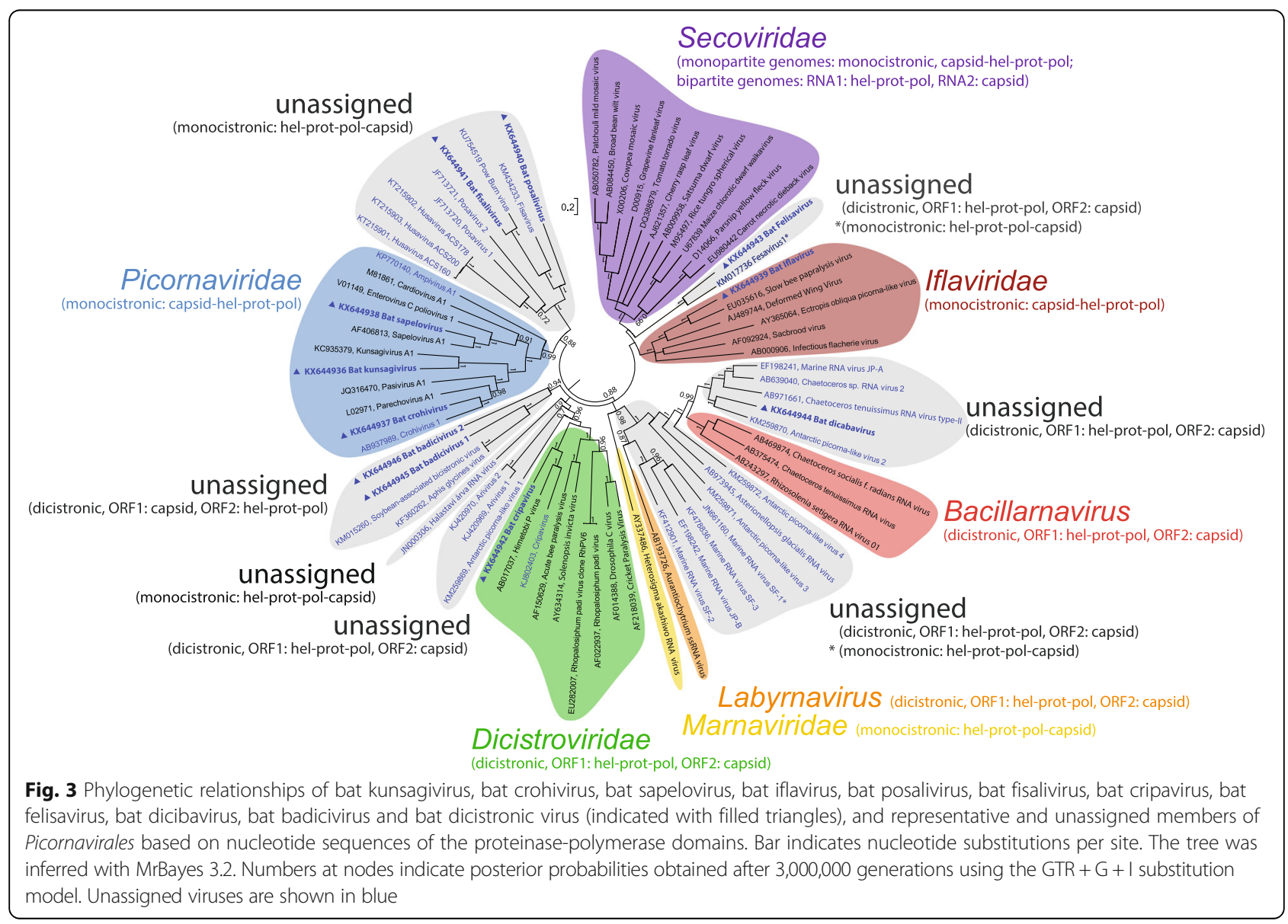


We further analyzed the phylogenetic relationships of the capsid proteins (Additional file 1: Figure S1). In order to ensure that only orthologous proteins were included, five distinct alignments including more relevant reference strains were investigated: (i) picornaviruses and candidates, (ii) bacillarnaviruses, labyrnavirus, bat dicibavirus and other dicistronic viruses with ORF2-encoded capsid proteins, (iii) insect dicistroviruses of the genera Cripavirus and Aparavirus and bat cripavirus, (iv) monocistronic viruses with $\mathrm{C}$-terminal capsid proteins (husa-, posa-, fisaviruses, Pow Burn virus of Drosophila subobscura, bat fisalivirus and bat posalivirus), and (v) insect iflaviruses and bat iflavirus. Due to the lack of representative sequence data for comparison, bat badiciviruses 1 and 2 and the bat felisavirus are not shown.

\section{Nucleotide composition analysis (NCA)}

Based on the mononucleotide and dinucleotide frequencies of a training dataset of 351 picorna-like viruses and their known host (mammalian, insects or plants) we performed a linear discriminant analysis (LDA) in an attempt to identify the most likely host of the viruses described in this paper. Based on the predicted LDA model, the classification and posterior probabilities of the viruses described in this paper were inferred (Fig. 4, Table 5). Bat kunsagivirus, sapelovirus and crohivirus clustered with picorna-like viruses that infect mammals, while bat badiciviruses 1 and 2 were found in the plant cluster. The rest of the viruses (bat felisavirus, fisalivirus, posalivirus, dicibavirus, iflavirus and cripavirus) clustered with picorna-like viruses known to infect insects. Posterior probabilities for the classification was greater than 0.9 for all newly identified viruses (Table 5 ).

\section{Discussion}

Using the NetoVIR protocol for viral metagenomics, we could retrieve the (nearly) complete genomes of eleven diverse and highly divergent viruses belonging to the order Picornavirales. Six out of these eleven viruses are likely to represent members of yet unassigned virus families of this order whereas bat crohivirus, bat sapelovirus, bat kunsagivirus, bat iflavirus, and bat cripavirus, belong to the established families Picornaviridae, Iflaviridae and Dicistroviridae.

Picornaviruses of the family Picornaviridae identified here were bat kunsagivirus, bat crohivirus and bat sapelovirus. The genome layout of bat kunsagivirus exhibits close similarity to that of roller kunsagivirus (species

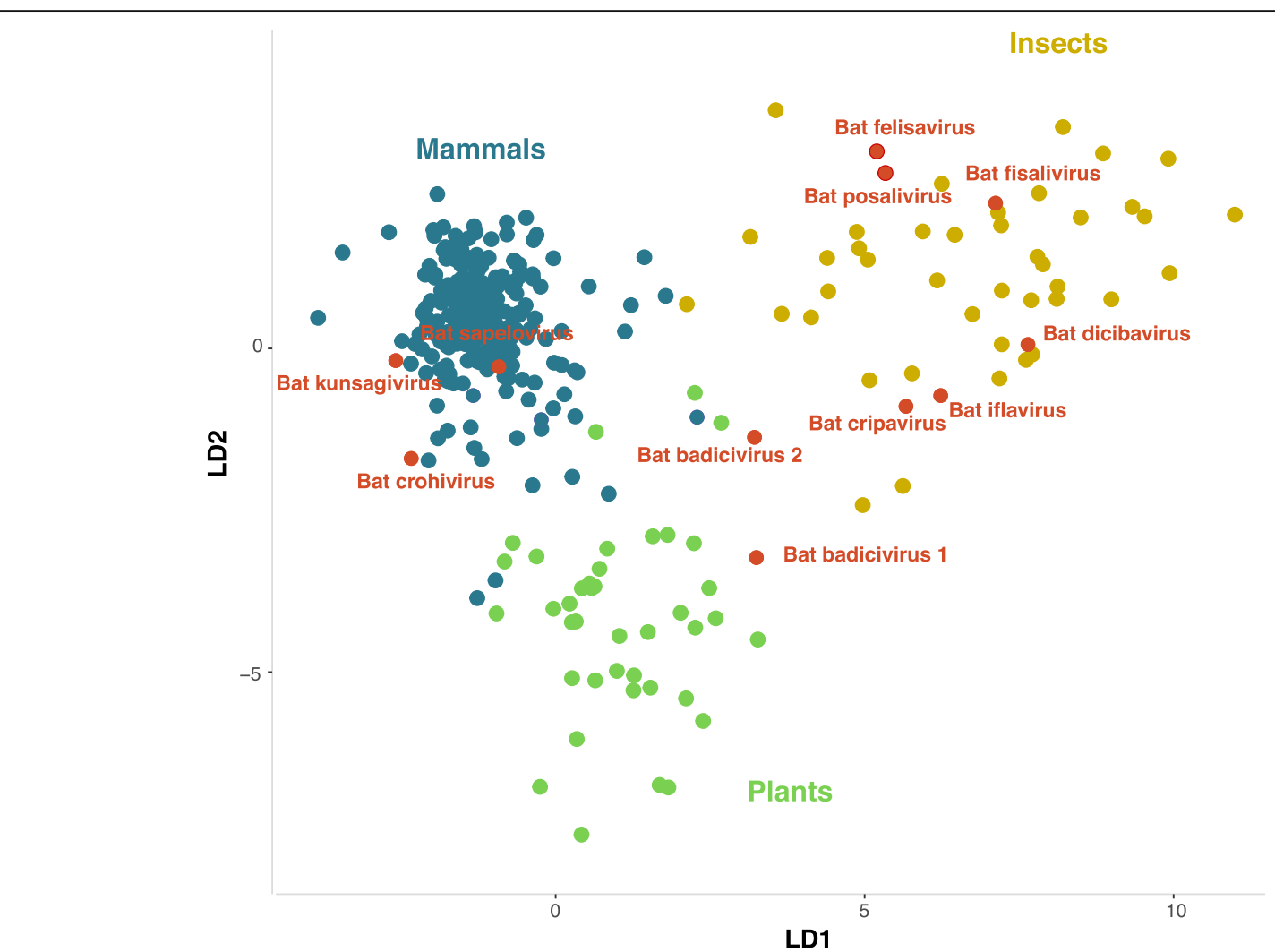

Fig. 4 Linear discriminant analysis employed in the classification of viral sequences into host groups. Graphs represent separation of groups using the most influential factors and points represent values for individual sequences 
Table 5 Posterior probability for the classification of the novel picorna-like sequences, based on linear discriminant analysis (LDA)

\begin{tabular}{llll}
\hline Virus & Mammals & Plants & Insects \\
\hline Bat_Kunsagivirus & 1.000 & 0 & 0 \\
Bat_crohivirus & 1.000 & 0 & 0 \\
Bat_sapelovirus & 1.000 & 0 & 0 \\
Bat_iflavirus & 0 & 0 & 1.000 \\
Bat_posalivirus & 0 & 0 & 1.000 \\
Bat_fisalivirus & 0 & 0 & 1.000 \\
Bat_cripavirus & 0 & 0 & 1.000 \\
Bat_felisavirus & 0 & 0 & 1.000 \\
Bat_dicibavirus & 0 & 0 & 1.000 \\
Bat_badicivirus_1 & 0 & 1.000 & 0 \\
Bat_badicivirus_2 & 0.043 & 0.914 & 0.044 \\
\hline
\end{tabular}

Kunsagivirus A) of the family Picornaviridae, but its deduced amino acid sequence exhibits significant differences suggesting classification into a novel species (proposed name "Kunsagivirus B"). The host of roller kunsagivirus was unclear as several rodent-related viruses were also detected in the same fecal sample, e.g. mosavirus, murine kobuvirus and Puumala virus (21). Therefore, a dietary origin of roller kunsagivirus could not be excluded. In line with this dietary hypothesis, bat kunsagivirus is predicted to have a mammalian host by NCA. Therefore, we speculate that fruit eating bats are most likely the host of the kunsagivirus identified in this study. Similarly, crohivirus (CroV1, AB937989), first isolated from a Zambian shrew [29] is a yet unclassified picornavirus with a pasivirus-like genome organization. The bat crohivirus has the same genome organization and shares the same features with the one from a shrew, although little sequence similarity may suggest a third pasivirus species. Just as bat kunsagivirus, bat crohivirus was also suggested to infect mammals according to the NCA. Thirdly, sapeloviruses make up a genus that comprises three species: Sapelovirus A, Sapelovirus B and Avian sapelovirus [34]. The novel sapelovirus is closely related to sapelovirus A1. In recent years, a number of sapelo-like viruses have been detected in the feces of bats, other mammals and birds [35-40]. Therefore, it is likely that bats are among the natural hosts of these viruses especially as the novel sapeloviruses identified in this study was predicted to have a mammalian host by the NCA. Due to the high diversity of sapeloviruses, a revision of the respective taxonomy is currently in progress.

Bat iflavirus is closely related to slow bee paralysis virus, belonging to the family Iflaviridae. The latter virus infects the honey bee and together with Varroa destructor virus may be critical for colony mortality [41]. All currently known iflaviruses infect insects. In addition, NCA suggests that the bat iflavirus has an insect host, and was therefore diet derived; despite the high number of iflavirus reads identified in the sample (Table 1). Therefore we speculate that bat iflavirus was the result of the consumption of fruits or leaves containing insects, larvae or eggs infected with this virus, as has been suggested before [42].

The bat monocistronic posalivirus and fisalivirus gene arrangements correspond to that of the monocistronic marnavirus. The genome of posalivirus depicts a multidrug and toxic compound extrusion (MATE) domains usually found only in bacteria [31]. These proteins are involved in active efflux of drugs from the cell thereby enabling resistance [43]. Given that the e-value was only $3.95 \mathrm{e}^{-03}$, the presence of these domains requires confirmation. Fisalivirus does not have this domain and is more fisavirus-like. Posaviruses 1 and 2, fisavirus 1, husavirus, bat posalivirus, and fisalivirus do not only have a similar gene arrangement but also cluster together in the 3CD phylogenetic tree (Fig. 3, 4d). They have a wide vertebrate host range as they were detected in feces of pigs (posaviruses) [9, 10], humans (husaviruses) [11], the intestinal content of a carp (fisavirus) [8] and now in feces of bats. Apart from that, an RdRPlike sequence closely related to posavirus 1 was also found in a cDNA library generated from RNA of Ascaris suum [9], a nematode parasitizing the pig intestine. Due to its presence in this nematodes, Shan and colleagues [9] postulated that posaviruses may be infecting these nematodes in the intestine of pigs. Whether posavirus really infects the round worm may be questioned, but a contamination of Ascaris with a porcine virus appears to be an alternative explanation. Our NCA analysis classified bat posali-, fisali- and felisavirus as insect infecting picorna-like viruses. However, since the training dataset did not contain viruses infecting nematodes, no final conclusions on the host can be made. Despite the current uncertainties about the origin of these posa-like viruses, they may constitute a new family in the order Picornavirales.

Bat cripavirus is closely related to Himetobi P virus, an insect picorna-like virus isolated from the small brown planthopper, Laodelphax striatellus [44]. Furthermore, another cripavirus was recently described (NB-1/2011/HUN, KJ802403), possessing five rather than three VPg genes, in the guano from an insectivorous bat, Pipistrellus pipistrellus [45]. Genetic relatedness and NCA, seem to suggest that bat cripavirus might be an insect virus, and therefore diet was the most likely source.

Bat felisavirus has a dicistronic genome with gene organization similar to viruses of the Dicistroviridae but only part of one rhv conserved domain could be identified in a conserved domain search. Phylogenetic analyses 
of the pro-pol domains revealed clustering with the fesavirus 1 (detected in clinically healthy cats) as closest relative [7]. There is only a partial fesavirus genome available (KM017736) but this virus has apparently a monocistronic genome layout whereas bat felisavirus displays two ORFs (Fig. 1). It is unclear yet whether fesavirus of cats has a distinct genome organization or whether a previous sequencing artefact could explain this difference. The intergenic region of bat felisavirus is rather short (52-75 nt). Therefore, it is unlikely that a dicistrovirus-like IGR-IRES mediates translation initiation of ORF2. Although NCA indicates an insect host for the bat felisavirus, identification of more closely related viruses with known host species would be needed to further validate this finding.

Bat dicibavirus, and badiciviruses 1 and 2 are other virus with a dicistronic genome. In each case, the two ORFs are separated by an IGR of 196, 457 and 227 nt, respectively, and the ORF2 starts with a glycine codon, which is typical for IGR-IRES driven translation initiation. However, characteristic secondary structures were not yet identified. Phylogenetic analyses (Fig. 3, Additional file 1: Figure S1) show that bat dicibavirus clusters together with marine picorna-like viruses which all infect marine protists and diatoms, and therefore, together with labyrnavirus and bacillarnavirus may form a new family of viruses in the Picornavirales. Both bat badiciviruses cluster with two insect viruses, Aphis glycines virus and soybean-associated bicistronic virus. This implies that the origin of this virus in bat stool remains obscure and is probably dietary. NCA analysis groups them within the insect cluster thereby indicating that they may be indeed insect viruses originating from the diet. Further, these viruses may also constitute a novel family in the order Picornavirales.

\section{Conclusion}

We were able to identify and characterize eleven novel and diverse RNA viruses of the order Picornavirales. This point to the considerable genetic variability of picorna-like viruses found in Eidolon helvum fruit bats. Bat kunsagivirus, crohivirus, and sapelovirus are clearly picornaviruses and this is consistent with the growing number of picornaviruses detected in bats. Many picornavirus infections cause a wide range of symptoms depending on virus-specific and hostspecific factors. Whether the affected bats were diseased, is unclear. The captured bats of the present study were apparently healthy without any obvious clinical symptoms. This, however, does not exclude the potential of these picornaviruses to induce diseases in their natural hosts or in other species after spillover infections.

Given that many severely pathogenic zoonotic viruses have been traced to originate from bats, the knowledge obtained in this study is valuable to rapidly trace potential future zoonotic infections from bats to humans. Furthermore, all bat samples analyzed here were collected from regions where people hunt, sell and eat bats, so coupled with the fact that the Picornaviridae family is made up of a vast amount of highly divergent human pathogens, zoonoses therefore are not unlikely. However, the potential of these viruses to infect humans remains to be investigated.

Bat iflavirus and cripavirus are viruses of the family Iflaviridae and Dicistroviridae, respectively, and are likely of an insect dietary origin. Bat posalivirus, bat fisalivirus, bat felisavirus, bat dicibavirus and bat badiciviruses 1 and 2, are unassigned members of the order Picornavirales, and their natural hosts is currently unclear, and remains to be determined.

\section{Additional file}

Additional file 1: Table S1. List of primers for genome completion. Table S2. Reference sequences used for composition analysis and differentiation of host groups. Figure S1. Phylogenetic relationships of orthologous capsid proteins: (A) P1 of picornaviruses (either 1A-1B-1C-1D or 1AB-1C-1D), (B) VP2-VP4-VP3-VP1 of bacillarnavirus, labyrnavirus and other viruses with a similar genome organization, (C) VP2-VP4-VP3-VP1 of dicistroviruses, (D) three capsid protein domains of yet unassigned, monocistronic viruses with C-terminal structural proteins (posa-, fisa-, husa-, bat posali- and fisalivirus, drosophila Pow Burn virus), and (E) VP2VP4-VP3-VP1 domains of iflaviruses. Bat viruses of this study are indicated by filled triangles. Unassigned viruses are printed in blue. Bars indicate nucleotide substitutions per site. The trees were inferred with MrBayes 3.2. Numbers at nodes indicate posterior probabilities obtained after $4,250,000$ generations (A), 3,000,000 generations (B), and 1,000,000 generations $(C, D, E)$. The $G T R+G+I$ substitution model was used for $(A, B)$, the GTR + G model was used for (C, D, E). (DOCX $188 \mathrm{~kb})$

\section{Abbreviations \\ CDD: Conserved domains database; CDNA: Complementary DNA; CRPV domain: Cricket paralysis virus capsid domain; Hel-Pro-Pol domain: Helicase- protease-polymerase domain; HIV: Human immunodeficiency virus; IGR: Intergenic region; IRES: Internal ribosome entry site; LDA: Linear discriminant analysis; NCA: Nucleotide composition analysis; NetoVIR: Novel enrichment technique of VIRomes; ORF: Open reading frame; Rhv domain: Rhinovirus capsid domain; RNA: Ribonucleic acid; UTR: Untranslated region}

\section{Acknowledgments}

CKY was supported by the Interfaculty Council for Development Cooperation (IRO) from the KU Leuven and NCN was supported by the Flanders Innovation \& Entrepreneurship ( $\mathrm{VLIO}$ ).

\section{Funding}

This work was supported by KU Leuven Grant EJX-C9928-StG/15/020BF. The Funding body was not involved in design of the study and collection, analysis, and interpretation of data and in writing the manuscript.

\section{Availability of data and materials}

The genomes reported here have been submitted to a public database (GenBank, SRA [https://www.ncbi.nlm.nih.gov/bioproject/PRJNA344863/]).

\section{Authors' contributions}

CKY, SMG, MVR and JM conceived and designed the study; CKY and SMG collected the samples; CKY, MZ, NCN and EH performed the experiments; CKY, WD, RZ, MZ, NCN, EH, NJK, PM and JM analyzed the data and drafted the manuscript. All authors read and approved the final manuscript. 


\section{Competing interests}

The authors declare that they have no competing interests.

\section{Consent for publication}

Not applicable.

\section{Ethics approval and consent to participate}

Ethical authorization for the protocol and the use of animal samples was obtained from the Cameroon National Ethics Committee, Yaoundé. All animal experiments were performed in accordance with the Ministry's National Ethics Committee guidelines. The bats were obtained from the South West Region of Cameroon using mist nets around fruit trees.

\section{Publisher's Note}

Springer Nature remains neutral with regard to jurisdictional claims in published maps and institutional affiliations.

\section{Author details}

'Department of Microbiology and Immunology, Rega Institute for Medical Research, Laboratory of Viral Metagenomics, KU Leuven - University of Leuven, Leuven, Belgium. ${ }^{2}$ Department of Microbiology and Immunology, Rega Institute for Medical Research, Laboratory for Clinical and Epidemiological Virology, KU Leuven - University of Leuven, Leuven, Belgium. ${ }^{3}$ Department of Virology and Antiviral Therapy, Jena University Hospital, Friedrich Schiller University, Jena, Germany. ${ }^{4}$ The Pirbright Institute, Ash Road, Pirbright, Woking, Surrey GU24 ONF, UK. ${ }^{5}$ Department of Biochemistry and Molecular Biology, Biotechnology Unit, Molecular and cell biology laboratory, University of Buea, Buea, Cameroon.

Received: 29 July 2016 Accepted: 16 March 2017

Published online: 23 March 2017

\section{References}

1. Le Gall O, Christian P, Fauquet CM, King AM, Knowles NJ, Nakashima N, Stanway G, Gorbalenya AE. Picornavirales, a proposed order of positivesense single-stranded RNA viruses with a pseudo-T $=3$ virion architecture. Arch Virol. 2008;153(4):715-27.

2. Chandrasekar $V$, Johnson JE. The structure of tobacco ringspot virus: a link in the evolution of icosahedral capsids in the picornavirus superfamily. Structure. 1998:6(2):157-71.

3. Christian P, Carstens E, Domier L, Johnson J, Johnson K, Nakashima N, Scotti P, Wilk Fvd: Dicistroviridae. In: Virus taxonomy, VIIlth Report of the ICTV. Edited by Fauquet CM, Mayo MA, Maniloff J, Desselberger U, Ball AL. London: Elsevier-Academic Press; 2005: 783-788.

4. Sanfacon H, Wellink J, Le Gall O, Karasev A, van der Vlugt R, Wetzel T. Secoviridae: a proposed family of plant viruses within the order Picornavirales that combines the families Sequiviridae and Comoviridae, the unassigned genera Cheravirus and Sadwavirus, and the proposed genus Torradovirus. Arch Virol. 2009; 154(5):899-907.

5. Abed Y, Boivin G. New Saffold cardioviruses in 3 children, Canada. Emerg Infect Dis. 2008;14(5):834-6.

6. Drexler JF, Luna LK, Stocker A, Almeida PS, Ribeiro TC, Petersen N Herzog P, Pedroso C, Huppertz HI, Ribeiro Hda Jr C, et al. Circulation of 3 lineages of a novel Saffold cardiovirus in humans. Emerg Infect Dis. 2008;14(9):1398-405

7. Zhang W, Li L, Deng X, Kapusinszky B, Pesavento PA, Delwart E. Faecal virome of cats in an animal shelter. J Gen Virol. 2014;95(Pt 11):2553-64.

8. Reuter G, Pankovics P, Delwart E, Boros A. A novel posavirus-related singlestranded RNA virus from fish (Cyprinus carpio). Arch Virol. 2015;160(2):565-8.

9. Shan T, Li L, Simmonds P, Wang C, Moeser A, Delwart E. The fecal virome of pigs on a high-density farm. J Virol. 2011;85(22):11697-708.

10. Hause BM, Hesse RA, Anderson GA. Identification of a novel Picornavirales virus distantly related to posavirus in swine feces. Virus Genes. 2015;51(1):144-7.

11. Oude Munnink BB, Cotten M, Deijs M, Jebbink MF, Bakker M, Farsani SM Canuti M, Kellam P, van der Hoek L. A novel genus in the order Picornavirales detected in human stool. J Gen Virol. 2015;96:3440-3.

12. Wang J, Czech B, Crunk A, Wallace A, Mitreva M, Hannon GJ, Davis RE. Deep small RNA sequencing from the nematode Ascaris reveals conservation, functional diversification, and novel developmental profiles. Genome Res. 2011;21(9):1462-77.
13. Yinda CK, Rector A, Zeller M, Conceição-Neto N, Heylen E, Maes P, Ghogomu SM, Van Ranst M, Matthijnssens J. A single bat species in Cameroon harbors multiple highly divergent papillomaviruses in stool identified by metagenomics analysis. Virol Rep. 2016:6:74-80.

14. Yinda CK, Zeller M, Conceicao-Neto N, Maes P, Deboutte W, Beller L, Heylen E, Ghogomu SM, Van Ranst M, Matthijnssens J. Novel highly divergent reassortant bat rotaviruses in Cameroon, without evidence of zoonosis. Sci Rep. 2016;6:34209.

15. Conceicao-Neto N, Zeller M, Lefrere H, De Bruyn P, Beller L, Deboutte W, Yinda CK, Lavigne R, Maes P, Van Ranst M, et al. Modular approach to customise sample preparation procedures for viral metagenomics: a reproducible protocol for virome analysis. Sci Rep. 2015;5:16532.

16. Marchler-Bauer A, Derbyshire MK, Gonzales NR, Lu S, Chitsaz F, Geer LY, Geer RC, He J, Gwadz M, Hurwitz DI, et al. CDD: NCBI's conserved domain database. Nucleic Acids Res. 2015:43(Database issue):D222-226.

17. Finn RD, Bateman A, Clements J, Coggill P, Eberhardt RY, Eddy SR, Heger A, Hetherington K, Holm L, Mistry J, et al. Pfam: the protein families database. Nucleic Acids Res. 2014;42(Database issue):D222-230.

18. Kelley LA, Mezulis S, Yates CM, Wass MN, Sternberg MJ. The Phyre2 web portal for protein modeling, prediction and analysis. Nat Protoc. 2015;10(6):845-58.

19. Tamura K, Peterson D, Peterson N, Stecher G, Nei M, Kumar S. MEGA5 molecular evolutionary genetics analysis using maximum likelihood, evolutionary distance, and maximum parsimony methods. Mol Biol Evol. 2011;28(10):2731-9.

20. Huelsenbeck JP, Ronquist F, Nielsen R, Bollback JP. Bayesian inference of phylogeny and its impact on evolutionary biology. Science. 2001:294(5550):2310-4.

21. Ronquist F, Huelsenbeck JP. MrBayes 3: Bayesian phylogenetic inference under mixed models. Bioinformatics. 2003:19(12):1572-4.

22. Kapoor A, Simmonds P, Lipkin Wl, Zaidi S, Delwart E. Use of nucleotide composition analysis to infer hosts for three novel picorna-like viruses. J Virol. 2010;84(19):10322-8.

23. Mihara T, Nishimura Y, Shimizu Y, Nishiyama H, Yoshikawa G, Uehara H, Hingamp P, Goto S, Ogata H. Linking Virus Genomes with Host Taxonomy. Viruses. 2016:8(3):66.

24. Karlin S, Mrazek J. Compositional differences within and between eukaryotic genomes. Proc Natl Acad Sci U S A. 1997:94(19):10227-32.

25. R Core Team. R: A language and environment for statistical computing. $R$ Foundation for Statistical Computing, Vienna, Austria, 2014. URL http:// www.R-project.org/.

26. Venables WN, Ripley BD. Modern Applied Statistics with S. New York: Springer; 2002.

27. Wickham H. ggplot2: Elegant Graphics for Data Analysis. New York: Springer; 2009

28. Boros A, Kiss T, Kiss O, Pankovics P, Kapusinszky B, Delwart E, Reuter G. Genetic characterization of a novel picornavirus distantly related to the marine mammal-infecting aquamaviruses in a long-distance migrant bird species, European roller (Coracias garrulus). J Gen Virol. 2013;94(Pt 9):2029-35.

29. Sasaki M, Orba Y, Ueno K, Ishii A, Moonga L, Hang'ombe BM, Mweene AS, Ito K, Sawa H. Metagenomic analysis of the shrew enteric virome reveals novel viruses related to human stool-associated viruses. J Gen Virol. 2015:96(Pt 2):440-52.

30. Krumbholz A, Dauber M, Henke A, Birch-Hirschfeld E, Knowles NJ, Stelzner A Zell R. Sequencing of porcine enterovirus groups $\|$ and III reveals unique features of both virus groups. J Virol. 2002;76(11):5813-21.

31. Hvorup RN, Winnen $B$, Chang AB, Jiang $Y$, Zhou XF, Saier Jr MH. The multidrug/oligosaccharidyl-lipid/polysaccharide (MOP) exporter superfamily. Eur J Biochem. 2003;270(5):799-813.

32. Chen Y, Nakashima N, Christian P, Bakonyi T, Bonning B, Valles S, Lightner D: Dicistroviridae. In: Virus Taxonomy: Classification and Nomenclature of Viruses: Ninth Report of the International Committee on Taxonomy of Viruses. Edited by King AMQ, Adams MJ, Carstens EB, Lefkowitz EJ. Amstardam: Elsevier Inc. ; 2011

33. Nakashima N, Uchiumi T. Functional analysis of structural motifs in dicistroviruses. Virus Res. 2009;139(2):137-47.

34. Knowles N, Hovi T, Hyypiä T, King A, Lindberg A, et al. Picornaviridae. In: King A, Adams M, Carstens E, Lefkowitz E, editors. Virus taxonomy: classification and nomenclature of viruses: Ninth Report of the International Committee on Taxonomy of Viruse. San Diego: Elsevier; 2012. p. 855-80.

35. Kemenesi G, Zhang D, Marton S, Dallos B, Gorfol T, Estok P, Boldogh S, Kurucz K, Oldal M, Kutas A, et al. Genetic characterization of a novel 
picornavirus detected in Miniopterus schreibersii bats. J Gen Virol. 2015;96(Pt 4):815-21.

36. Wu Z, Ren X, Yang L, Hu Y, Yang J, He G, Zhang J, Dong J, Sun L, Du J, et al. Virome analysis for identification of novel mammalian viruses in bat species from Chinese provinces. J Virol. 2012;86(20):10999-1012.

37. Lau SK, Woo PC, Lai KK, Huang Y, Yip CC, Shek CT, Lee P, Lam CS, Chan KH, Yuen KY. Complete genome analysis of three novel picornaviruses from diverse bat species. J Virol. 2011;85(17):8819-28.

38. Woo PC, Lau SK, Choi GK, Huang Y, Sivakumar S, Tsoi HW, Yip CC, Jose SV, Bai R, Wong EY, et al. Molecular epidemiology of canine picornavirus in Hong Kong and Dubai and proposal of a novel genus in Picornaviridae. Infect Genet Evol. 2016;41:191-200.

39. Pankovics P, Boros A, Reuter G. Novel picornavirus in domesticated common quail (Coturnix coturnix) in Hungary. Arch Virol. 2012;157(3):525-30.

40. Kofstad T, Jonassen CM. Screening of feral and wood pigeons for viruses harbouring a conserved mobile viral element: characterization of novel Astroviruses and Picornaviruses. PLoS One. 2011;6(10):e25964

41. de Miranda JR, Dainat B, Locke B, Cordoni G, Berthoud H, Gauthier L, Neumann P, Budge GE, Ball BV, Stoltz DB. Genetic characterization of slow bee paralysis virus of the honeybee (Apis mellifera L.). J Gen Virol. 2010;91(Pt 10):2524-30.

42. Webala PW, Musila S, Makau R. Roost occupancy, roost site selection and diet of straw-coloured fruit bats (Pteropodidae:Eidolon helvum) in western Kenya: the need for continued public education. Acta Chiropterologica. 2014;6(1):86-94.

43. Putman M, van Veen HW, Konings WN. Molecular properties of bacterial multidrug transporters. Microbiol Mol Biol Rev. 2000;64(4):672-93.

44. Nakashima N, Sasaki J, Toriyama S. Determining the nucleotide sequence and capsid-coding region of himetobi $\mathrm{P}$ virus: a member of a novel group of RNA viruses that infect insects. Arch Virol. 1999;144(10):2051-8.

45. Reuter G, Pankovics P, Gyongyi Z, Delwart E, Boros A. Novel dicistrovirus from bat guano. Arch Virol. 2014;159(12):3453-6.

\section{Submit your next manuscript to BioMed Central and we will help you at every step:}

- We accept pre-submission inquiries

- Our selector tool helps you to find the most relevant journal

- We provide round the clock customer support

- Convenient online submission

- Thorough peer review

- Inclusion in PubMed and all major indexing services

- Maximum visibility for your research

Submit your manuscript at www.biomedcentral.com/submit

) Biomed Central 